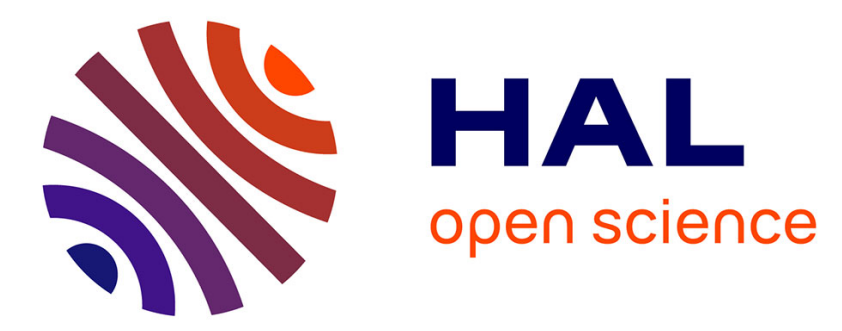

\title{
Process simulation and energetic analysis of different supercritical water gasification systems for the valorisation of biomass
}

Félicité Ondze, Jean-Henry Ferrasse, Olivier Boutin, Jean-Christophe Ruiz, Frédéric Charton

\section{To cite this version:}

Félicité Ondze, Jean-Henry Ferrasse, Olivier Boutin, Jean-Christophe Ruiz, Frédéric Charton. Process simulation and energetic analysis of different supercritical water gasification systems for the valorisation of biomass. Journal of Supercritical Fluids, 2018, 133, pp.114 - 121. 10.1016/j.supflu.2017.10.002 . hal-02115423

\section{HAL Id: hal-02115423 \\ https://hal.science/hal-02115423}

Submitted on 30 Apr 2019

HAL is a multi-disciplinary open access archive for the deposit and dissemination of scientific research documents, whether they are published or not. The documents may come from teaching and research institutions in France or abroad, or from public or private research centers.
L'archive ouverte pluridisciplinaire HAL, est destinée au dépôt et à la diffusion de documents scientifiques de niveau recherche, publiés ou non, émanant des établissements d'enseignement et de recherche français ou étrangers, des laboratoires publics ou privés. 


\title{
Process simulation and energetic analysis of different supercritical water gasification systems for the valorisation of biomass
}

\author{
Félicité Ondze $^{\mathrm{a}}$, Jean-Henry Ferrasse ${ }^{\mathrm{b}}$, Olivier Boutin ${ }^{\mathrm{b}, *}$, Jean-Christophe Ruiz ${ }^{\mathrm{a}}$, \\ Frédéric Charton $^{\mathrm{a}}$ \\ a CEA, DEN, Marcoule, F-30207 Bagnols sur Cèze Cedex, France \\ b Aix Marseille Univ, CNRS, Centrale Marseille, M2P2, Marseille, France
}

G R A P H I C A L A B S T R A C T

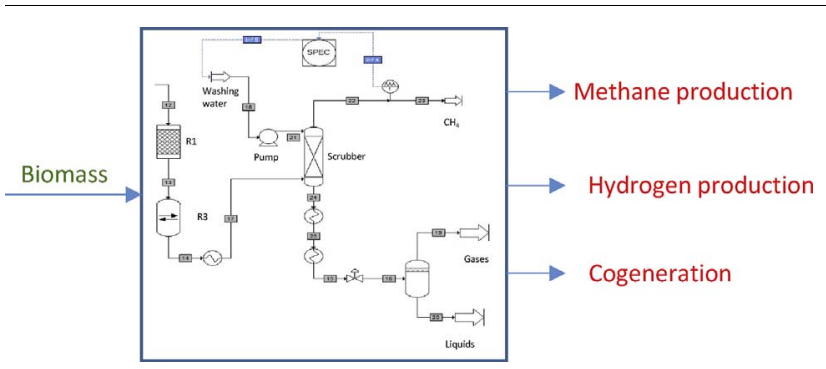

\section{A R T I C L E I N F O}

\section{Keywords:}

Biomass gasification

Process simulation

Energetic optimisation

Hydrogen

Methane

Cogeneration

\begin{abstract}
A B S T R A C T
The energetic efficiency for the supercritical gasification of biomass is studied for three cases: hydrogen and methane production, heat and electricity cogeneration. Experimental results from the gasification of glucose are used to represent the gasifier. The other unit operations are simulated using the software ProsimPlus through thermodynamic equilibrium calculations. Simulations are conducted at different pressure, temperature and initial biomass concentration. The energetic and exergetic yields are calculated, as well as the minimum heat requirement estimated from a pinch analysis. All the results are then exploited to determine optimal conditions for two systems: adiabatic and isothermal. The optimal temperature ranges from 584 to $626^{\circ} \mathrm{C}$, whereas the optimal initial concentration ranges from 51 to $87 \mathrm{~g} \mathrm{~L}^{-1}$. The system giving the best result in term of global energetic optimisation is methane production in isothermal conditions, followed by methane production in adiabatic conditions. The optimal energy efficiencies are $94 \%$ and $91 \%$ respectively.
\end{abstract}

\section{Introduction}

Among different processes of biomass conversion, an attractive way is gasification: the "dry" gasification, which operates at high temperature (up to $950{ }^{\circ} \mathrm{C}$ ) and a pressure close to atmospheric pressure, and supercritical water gasification (SCWG) with temperature ranging from 450 to $600^{\circ} \mathrm{C}$ and pressure up to $40 \mathrm{MPa}$. This last one is more specifically dedicated to wet biomass as no pre-drying step is needed.
Gasification in supercritical water can be used for the production of hydrogen [1-3]. However a mixture of carbon monoxide, hydrogen and methane are generally obtained depending on the operating conditions [4-6]. Gas compositions from experimental results for various biomass or chemical compounds are available and specific calculations have been performed to predict gas composition at thermodynamic equilibrium [7-9]. Equilibrium predictions are in accordance with experimental data when light gas molecules are considered but are not of use

\footnotetext{
* Corresponding author at: Laboratoire M2P2, UMR CNRS 7340, Bâtiment Laennec, BP 80, 13545 Aix-en-Provence Cedex 4, France.

E-mail address: olivier.boutin@univ-amu.fr (O. Boutin).
} 
when bigger molecules are presents in complex mixtures.

Regarding conventional lignocellulosic biomass, it is generally accepted that glucose is a model compound for cellulose (also sometimes for hemicellulose), aromatic compounds a model for lignin and glycine a model for protein [10]. A study of many different biomass of agricultural origin shows the wide range of results and the difficulty of predicting yields regarding the composition of the initial biomass [11]. For residues, SCWG has been tested for industrial effluent: black liquor from paper mills, food industry or municipal in the case of sewage sludge with massic water content higher than $90 \%$. Yakaboylu et al. [12] and Casademont et al. [13] provide a complete overview on biomass gasification, from experimental approaches to modelling.

Contrary to the important quantity of experimental results for SCWG of biomass, less studies have paid attention to the use of experimental results for a global energetic analysis of the systems, from the raw biomass to the final useful product. In literature, first approaches are based on the estimation of overall energy balances. For instance, a classical and complete approach on energetic evaluation has been proposed by Marias et al. [14]. The same kind of work have been conducted by Guan et al. [15] for partial oxidation of biomass. However, these works are dedicated only to the gasification reactor and not to the complete system up to the production of the final useful gas. A more complete study including other unit operations, up to the production of a syngas, is proposed by Wan [16]. Different operating parameters have been tested, the different stages being modelled through thermodynamic equilibrium. However, in all these studies, a systemic study of the operating conditions as well as an optimisation for the gas production are not developed.

This work presents the evaluation of three scenarios (production of hydrogen, production of methane and cogeneration) simulated using a commercial software, based on experimental data for the gasification reactor and mainly thermodynamic equilibrium for other operation units. These simulations give energy and exergy yields, and along with a Pinch analysis, the minimum energy required for each case studied. Eventually, using a numerical design approach, the influence of operating conditions on these three parameters is studied.

\section{Process simulations}

Process simulations have been carried out with the numerical simulation software ProSimPlus (version 3.5.18, France). This software allows the calculation of mass and energy balances for each unit operation. It is also a data bank for the physical properties of the different compounds considered. Except for supercritical gasification, process units are mainly calculated with thermodynamic equilibrium using Predictive Soave Redlich Kwong model. For few cases, another thermodynamic model can be used; this model being indicted in the text. Experimental data from the supercritical water gasification of glucose are used at the entering and the exit of the gasifier [17]. For the three scenarios, the different unit operation are calculated either as an isothermal system or an adiabatic system. Detailed conversion systems are given bellow. A brief description of the simulation tool is given in the Supplementary materiel, Appendix A.

\subsection{Gasifier}

The simulation of the generation of gases from the gasification reactor is common to the three scenarios. The data correspond to the experimental results obtained from the gasification of glucose [17]. The gasifier is fed by a glucose solution with a flowrate of $1 \mathrm{~kg} \mathrm{~h}^{-1}$ (Flow 1 in Fig. 1). The initial concentration of Total Organic Carbon (TOC) varies from 20 to $80 \mathrm{~g} \mathrm{~L}^{-1}$. The incoming flow is pressurized by a high pressure pump (HP pump on Fig. 1) having an isentropic efficiency of $90 \%$. The stream (2) is then preheated between 450 and $600{ }^{\circ} \mathrm{C}$. The gasification reactor (GR) is simulated by a subroutine considering experimental conversion rates: a balance equation is written for each experimental condition tested on glucose. Indeed, as a matter of fact, equilibrium composition cannot be used due to the remaining carbon in the experimental results. All balance equations used in the gasifier module are presented in the supporting Information part (Supplementary material, Appendix B). For example, for the simulation of the production of gas at $600{ }^{\circ} \mathrm{C}$ with an initial glucose solution of $20 \mathrm{~g} \mathrm{~L}^{-1}$, the following reaction is considered (Eq. (1)).

$\mathrm{C}_{6} \mathrm{H}_{12} \mathrm{O}_{6}+2.04 \mathrm{H}_{2} \mathrm{O} \rightarrow 3.65 \mathrm{CO}_{2}+0.33 \mathrm{C}_{2} \mathrm{H}_{6}+5.06 \mathrm{H}_{2}+0.88$
$\mathrm{CH}_{4}+0.66 \mathrm{CO}+0.08 \mathrm{C}_{2} \mathrm{H}_{6} \mathrm{O}$

The last term " $\mathrm{C}_{2} \mathrm{H}_{6} \mathrm{O}$ " (ethanol) is added to the equation in order to complete the atom balance and to fulfil with experimental results. Indeed, for each conversion, the mass balance and the atom balance on $\mathrm{C} \mathrm{H}$ and $\mathrm{O}$ is calculated. In order to fulfil all atom balance another compounds has to be used. The use of ethanol, in this case, allows to make atom balance correct and are consistent with the remaining TOC of liquids after conversion. Compounds in the outlet are not quantified except by TOC measurement. The heat of reaction accompanying gasification is calculated on the basis of the balance equation using the enthalpy of formation of the various compounds. The stream leaving the reactor (4) is fed to a two-phase separator downstream with an overflow valve and a cold heat exchanger.

\subsection{Hydrogen production}

For hydrogen production, the different stages of enrichment and purification are based on the data from literature [18-20]. Fig. 1 shows the system for hydrogen production from biomass, including the gasifier reactor.

The gasification reactor outlet stream (6) is cooled down and is separated by a liquid flash stream (LF1) at given temperature and pressure. The temperature specification (noted "SPEC" on Fig. 1) is performed on the ratio of the flow of water necessary for the enrichment step over the flow of gaseous carbon (flux 10). It reduces both the heat needed for flux 11 and the $\mathrm{CO}_{2}$ content in the gas mixture at the outlet of the separator. Remaining gases consist of $\mathrm{H}_{2}, \mathrm{H}_{2} \mathrm{O}, \mathrm{CO}_{2}, \mathrm{CO}$, $\mathrm{CH}_{4}$ and $\mathrm{C} 2-\mathrm{C} 4$ at a pressure of $3 \mathrm{MPa}$ and in varying proportions depending on the temperature of the gasification reactor. At this step, the hydrogen flow ranges from 1.5 to $8 \mathrm{~g} \mathrm{~h}^{-1}$ and represents from 5 to $30 \mathrm{~mol} \%$ of the producted gas, for a temperature range between 450 and $600{ }^{\circ} \mathrm{C}$ in the gasification reactor.

To increase hydrogen concentration in the mixture an enrichment step consists of two hydrocarbons reforming reactors in series:

$\mathrm{CH}_{4}+\mathrm{H}_{2} \mathrm{O} \leftrightarrow \mathrm{CO}+3 \mathrm{H}_{2}$

i- A reforming reactor for light hydrocarbons (R1). For instance, the reforming of methane to hydrogen is simulated by steam reforming reactions through Eq. ((2) and (3)).

$\mathrm{CH}_{4}+\mathrm{H}_{2} \mathrm{O} \leftrightarrow \mathrm{CO}+3 \mathrm{H}_{2}$

$\mathrm{CH}_{4}+2 \mathrm{H}_{2} \mathrm{O} \leftrightarrow \mathrm{CO}_{2}+4 \mathrm{H}_{2}$

Under the conditions of temperature and pressure of $3 \mathrm{MPa}$ and $700{ }^{\circ} \mathrm{C}$, the formation of coal that may occur during the process of reforming [18] is avoided.

ii- A reforming reactor for CO (R2), following Eq. (4) (water gas shift reaction):

$\mathrm{CO}+\mathrm{H}_{2} \mathrm{O} \leftrightarrow \mathrm{CO}_{2}+\mathrm{H}_{2}$

For other hydrocarbons, stoichiometric equations are written and the excess of initial water is used for reactions. The gaseous mixture is then cooled to separate residual water from the product gas (LF2) prior to final purification of the hydrogen stream. After this step, the gaseous 


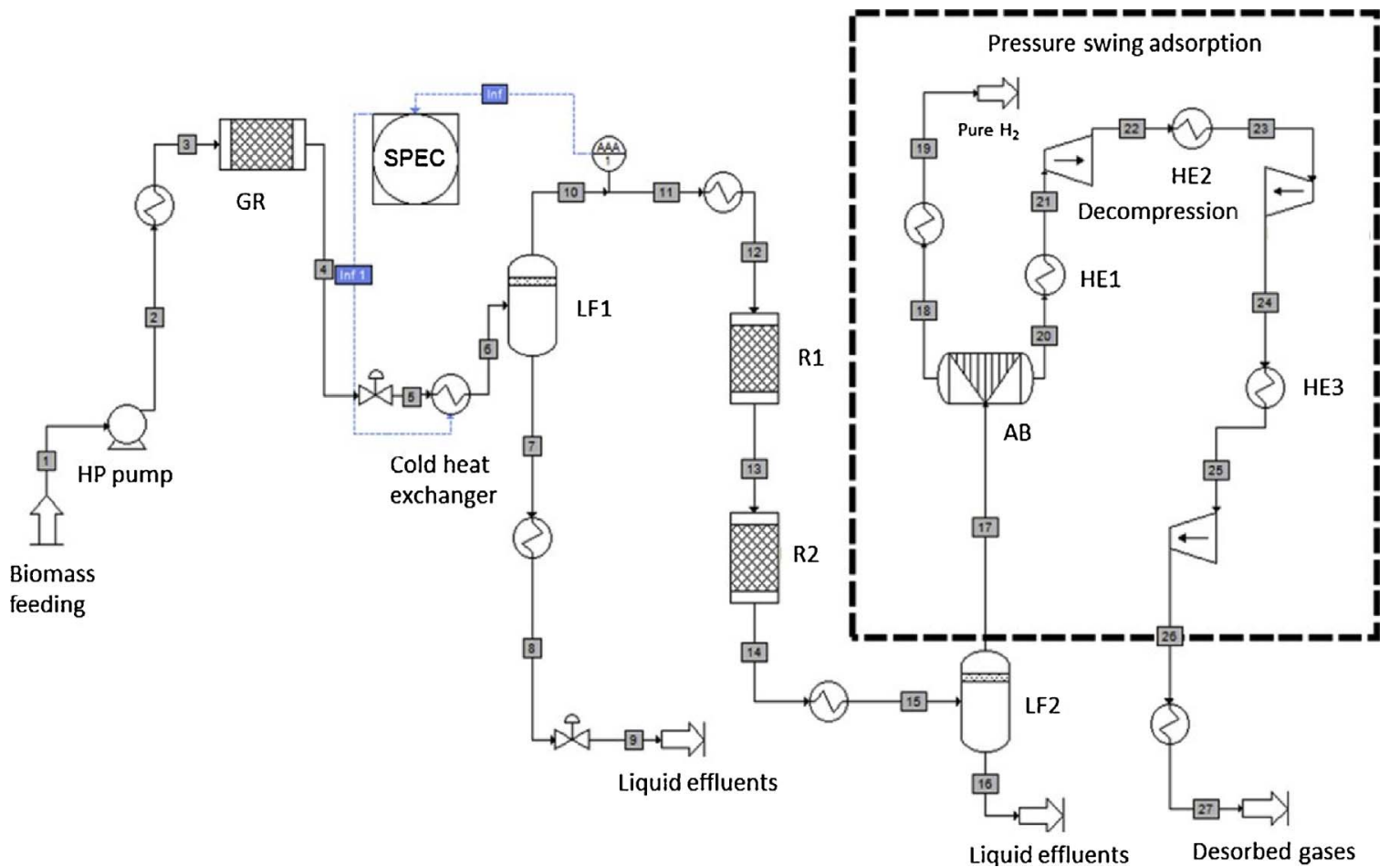

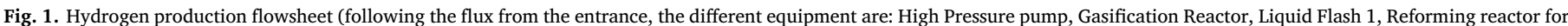

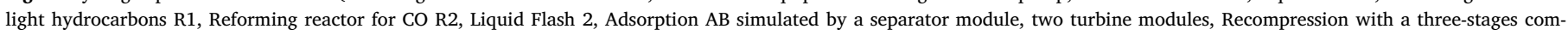
pressor, Heat exchangers HE 1, 2 and 3).

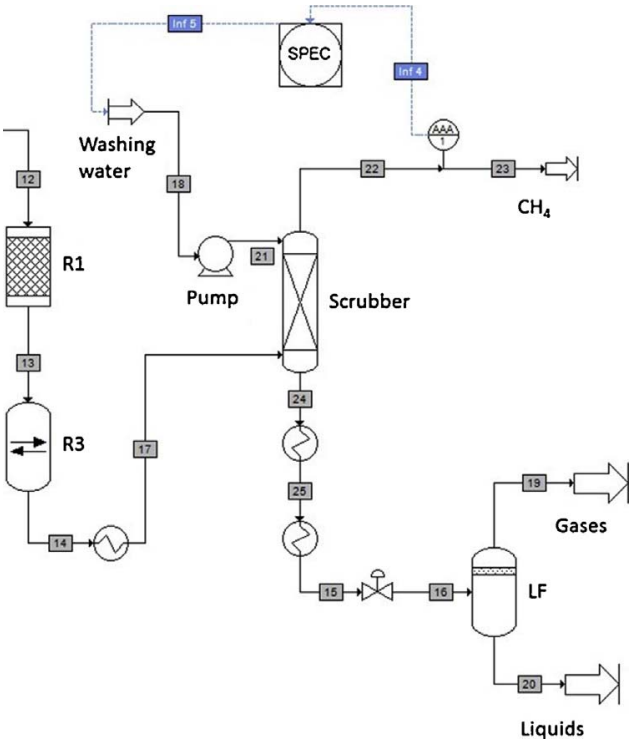

Fig. 2. Methane production flowsheet (R1: Hydrocarbons reforming, other than methane, $\mathrm{CO}$ and $\mathrm{H}_{2}$ reforming R3, absorption column Scrubber of 15 plates, Liquid Flash).

mixture (flux 17) has a composition closed to $70 \%$ molar $\mathrm{H}_{2}$ and $30 \%$ molar $\mathrm{CO}_{2}$.

The last step is the purification of hydrogen produced using the PSA (pressure swing adsorption) cycle: pressures between 0.3 and $3.4 \mathrm{MPa}$ at temperatures between 20 and $30^{\circ} \mathrm{C}$. The PSA is set according to ref [19]. The process is simulated as a continuous process where both discontinuous effect are simultaneously considered. The continuity of the operation result in the implementation of two adsorbent beds with alternating operations (noted AB on Fig. 1). PSA cycle has four phases: adsorption, depressurization, regeneration or low pressure purge and recompression. The phases are simulated as follows:
- Adsorption (AB) is simulated by the separator module component in which hydrogen is separated at $3 \mathrm{MPa}$ with a recovery rate of $90 \%$ [19].

- Depressurization and regeneration are simulated by two turbine modules in series with respective pressure loss of 2 and $0.9 \mathrm{MPa}$, to release the adsorbed gas.

- Recompression is simulated by a three-stage compressor with integrated cooling systems. This module compresses the gas from 0.1 to $3 \mathrm{MPa}$.

Heat exchangers (HE 1, 2 and 3 on Fig. 1) inserted between the stages maintain the temperature of the gases at the dew point of the mixture. Mass and energy balances from these simulations allow the calculation of the different yields. The maximum flow rate of hydrogen produced is $23 \mathrm{gh}^{-1}$ (for an input flow of $200 \mathrm{gh}^{-1}$ of dry matter). At the end of the process, hydrogen is cooled down to ambient temperature before exiting the process. All the calculated data for hydrogen production (vapour fractions, mass flows, stream composition ...) are given in Supplementary material, Appendix C.

\subsection{Methane production}

Several studies on the production of methane from biomass are proposed in the literature. Industrial processes of methane production are often biological processes such as fermentation. Thermochemical processes are still under investigation [21-25]. Fig. 2 shows the flowsheet of the process of methane production from flux 12, the first part being the same as on Fig. 1.

Following the gasification reactor, a first separation step is proposed. The separation of gaseous and liquid effluents is different from that of $\mathrm{H}_{2}$ production. The separation temperature and the flow rate required for the step of enrichment of the gas mixture to methane in the $\mathrm{R} 1$ and $\mathrm{R} 3$ reactors are obviously different. The supercritical mixture is expanded to $2.5 \mathrm{MPa}$ to satisfy the conditions for reforming hydrocarbons, other than methane, to $\mathrm{CO}$ at $370{ }^{\circ} \mathrm{C}$ (R1). This is followed by 
the methanation reaction between $\mathrm{CO}$ and hydrogen in reactor R3, respecting thermochemical equilibrium, which increases the amount of methane up to $25 \mathrm{~mol} \%$. The mole fraction of methane produced does not exceed $50 \%$ of the gas mixture in the different conditions tested. The entire carbon is converted to methane and $\mathrm{CO}_{2}$.

The next step is the purification of the gas. The purification process must operate at high pressure as the pressure of the gas exiting the methanation reactor varies from 5 to $15 \mathrm{MPa}$. The removal of $\mathrm{CO}_{2}$ in the gas mixture depends on the partial pressure of $\mathrm{CO}_{2}$ and the purity of the final product. When the mole fraction of $\mathrm{CO}_{2}$ is higher than $40 \%$ in the gas mixture, three techniques are identified: physical absorption, membrane processes and PSA. The first two are suitable for injection at $5 \mathrm{MPa}$, while the PSA operates at $3 \mathrm{MPa}$. Due to these specifications, the purification system is simulated by an absorption column (Scrubber on Fig. 2) of 15 plates; the gas mixture reaches the bottom of the column at $100{ }^{\circ} \mathrm{C}$. Methane at the outlet of the scrubber is obtained with a purity up to $99 \%$ by weight. The purity is controlled by the flowrate of solvent used (water + methyl diethanolamine, represented with the thermodynamic model "amine and acid gas" in Prosim software). It reaches room temperature under a pressure of $15 \mathrm{MPa}$ at the outlet. This high pressure is kept high to allow the gas to join gas pipeline. The absorbed gases are released downstream of the washing column by performing a low-pressure flash. The solvent may then be regenerated and recycled (this point is not evaluated in this study). All the calculated data for hydrogen production (vapour fractions, mass flows, stream composition ...) are given in Appendix D.

\subsection{Production of electricity and heat (cogeneration)}

Fig. 3 shows the flowsheet of this process from flux 12, the first part being the same as on Fig. 1. The thermodynamic cycle selected for the production of electricity is a simple cycle consisting of a compressor, a combustor and a gas turbine. As previous systems, pressurization, compression and turbine are simulated with an isentropic efficiency of $90 \%$. Air (flux 11) is compressed at the same pressure than the separator outlet (flux 12). Preheating of the air and gas mixture is performed at $120^{\circ} \mathrm{C}$ if necessary. In the combustion chamber, all the gas is completely oxidised to $\mathrm{CO}_{2}$ and water. A second specification is performed on the air supply to set the oxygen level to a normalized value of

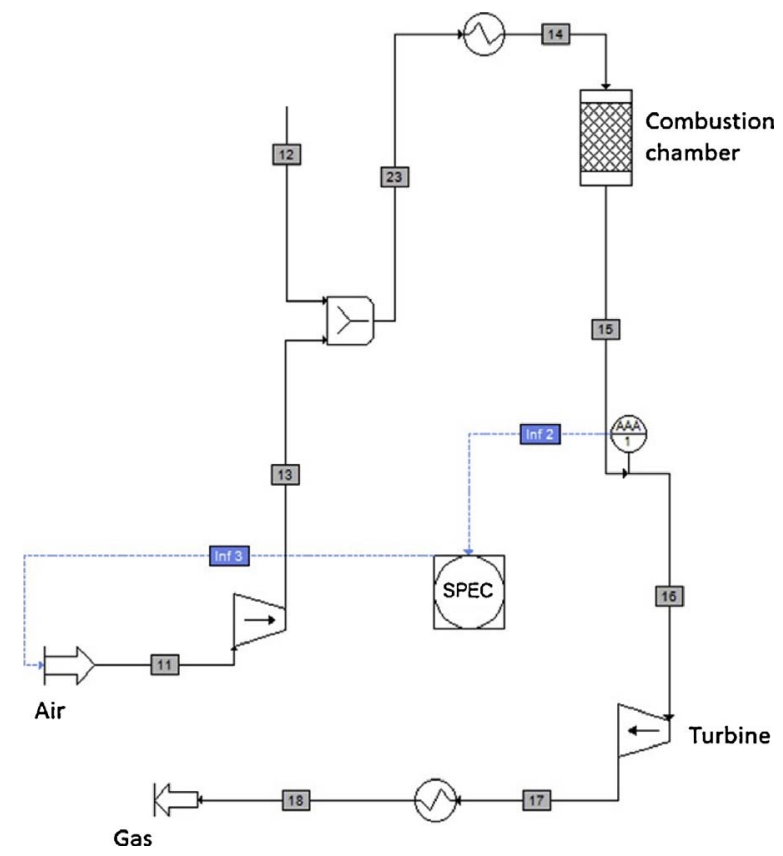

Fig. 3. Heat recovery and electricity production flowsheet (mixing flux, combustion chamber, and turbine). emission in the atmosphere at a molar fraction of 0.06 in the fumes. Heat available in the fumes is calculated by adding an heat exchanger cooling down the fumes to ambient temperature. In isothermal conditions, a steam utility is used to remove heat, and added to heat generation system. The adiabatic system differs from the isothermal system by specifying the outlet temperature. The outlet temperature of combustion chamber in the adiabatic system can reach $1500{ }^{\circ} \mathrm{C}$.

All the calculated data for heat and electricity production (vapour fractions, mass flows, stream composition ...) are given in Appendix E.

\section{Results and discussion}

\subsection{Pinch analysis}

An approach to facilitate energy integration is the pinch method analysis $[26,27]$. This method analyses the possible heat exchange between the cold fluids (which require the application of heat) and the hot fluids (which can dissipate heat) in order to minimize irreversibilities in the process. On these curves, the point where hot and cold curves are close is the pinch point. These data are combined to build the cold composite curves for all common cold and hot composite curves for all the warm currents. At the pinch point, the temperature gap is set at $10{ }^{\circ} \mathrm{C}$. This method enables the calculation of the minimum heat requirement (MER) for the system.

The pinch analysis is realised for all scenarios and for different configuration of reactors (isothermal or adiabatic) and operating conditions (temperature, inlet concentration of glucose). All the data are taken from the simulations presented in the previous part, giving the different heat flux exchanges. A result of typical composite curve (hot and cold) is drawn in Fig. 4 for hydrogen production, while the typical grand composite curve for each scenarios is proposed in Fig. 5.

In the adiabatic cogeneration system (Fig. 5), results show that it is no need to supply heat. This is due to the complete combustion of organic matter in the combustion chamber that totally compensates the energy demand for the gasification part, slightly endothermic in this case. The highest energy requirement is observed for hydrogen production and is explained by the two endothermic reactors (gasification and hydrocarbons reforming). To produce methane, the energy required is less important than that needed for hydrogen production.

A comparison of the minimum energy required in several configuration is presented in Table 1 for gas production, while net electric production and cold minimum energy is presented for the cogeneration configuration. The adiabatic or isothermal cases are considered in the gasification reactor, reforming reactors and combustion chamber reactors.

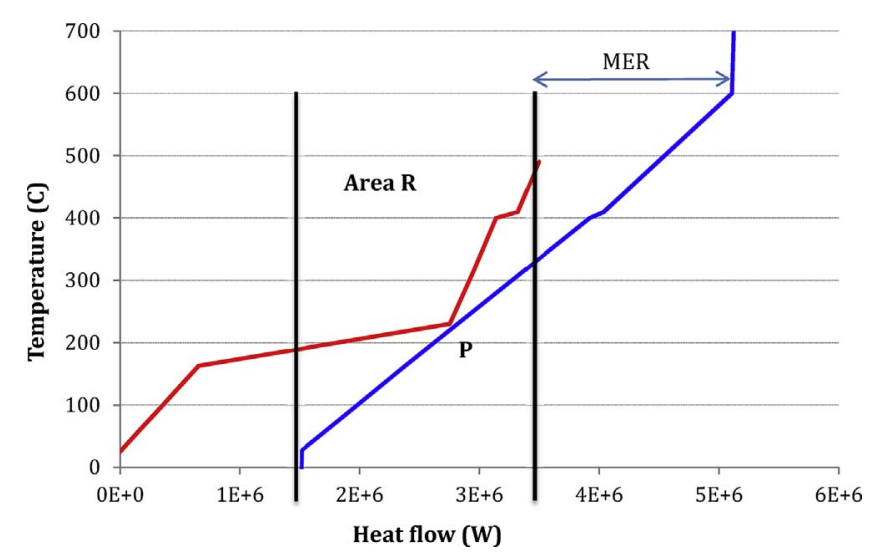

Fig. 4. Example of pinch analysis. The composite hot (in red) and cold (in blue) curves for the simulation of $\mathrm{H} 2$ production (TOC concentration $20 \mathrm{~g} \mathrm{~L}^{-1}$; gasification reactor temperature $600{ }^{\circ} \mathrm{C}$; temperature gap is set at $10^{\circ} \mathrm{C}$; P letter on the graph represents the pinch point; area $\mathrm{R}$ indicates the overlap area). (For interpretation of the references to colour in this figure legend, the reader is referred to the web version of this article.) 


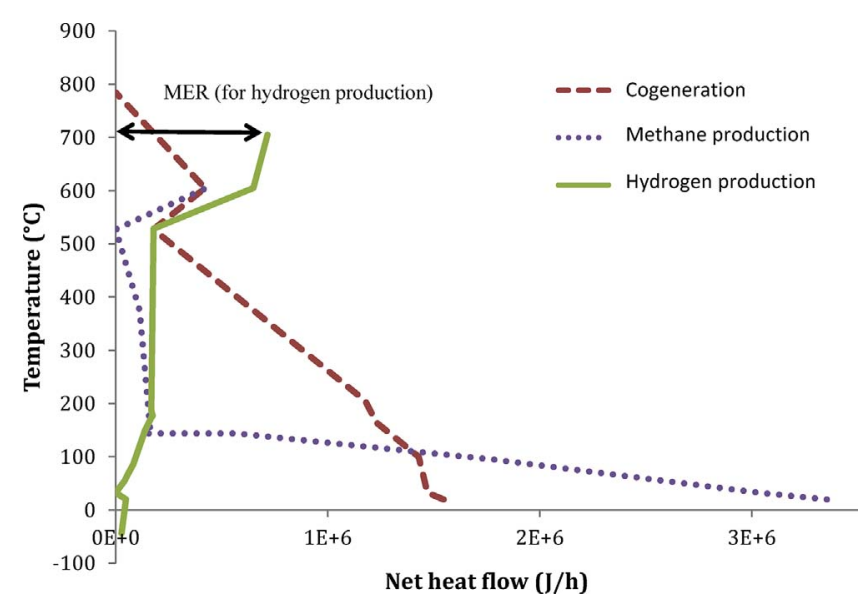

Fig. 5. Grand composite curves obtained for the three studied systems at isothermal and adiabatic conditions (TOC $20 \mathrm{gL}^{-1}$; gasification reactor temperature $600{ }^{\circ} \mathrm{C}$ ).

Table 1

Minimum energy requirement (MER) in W for gases production, net electricity production and minimum cooling requirement for cogeneration.

\begin{tabular}{|c|c|c|c|c|c|c|c|c|c|c|}
\hline \multirow{2}{*}{\multicolumn{2}{|c|}{$\begin{array}{l}\text { Exp. number } \\
\text { GR temperature }{ }^{\circ} \mathrm{C} \\
\text { COT concentration } \mathrm{g} \mathrm{L}^{-1}\end{array}$}} & \multicolumn{4}{|c|}{450} & \multicolumn{2}{|l|}{500} & \multicolumn{3}{|c|}{600} \\
\hline & & 20 & 30 & 60 & 80 & 20 & 20 & 30 & 60 & 80 \\
\hline \multirow[t]{4}{*}{ Adiabatic } & $\mathrm{H}_{2}$ & 432 & 422 & 412 & 408 & 339 & 205 & 188 & 167 & 199 \\
\hline & $\mathrm{CH}_{4}$ & 430 & 425 & 397 & 419 & 337 & 202 & 178 & 144 & 118 \\
\hline & $\begin{array}{l}\text { Cogeneration } \\
\left(Q_{\text {cold }}\right)\end{array}$ & 53 & 94 & 203 & 237 & 60 & 85 & 138 & 269 & 413 \\
\hline & $P_{\text {elec }}$ & 15 & 38 & 56 & 147 & 20 & 37 & 72 & 166 & 264 \\
\hline \multirow[t]{4}{*}{ Isothermal } & $\mathrm{H}_{2}$ & 405 & 384 & 356 & 309 & 273 & 174 & 150 & 127 & 198 \\
\hline & $\mathrm{CH}_{4}$ & 382 & 349 & 282 & 242 & 277 & 161 & 123 & 63 & 67 \\
\hline & $\begin{array}{l}\text { Cogeneration } \\
\left(\mathrm{Q}_{\text {cold }}\right)\end{array}$ & 64 & 114 & 256 & 297 & 40 & 102 & 166 & 326 & 509 \\
\hline & $\mathrm{P}_{\text {elec }}$ & 5 & 18 & 63 & 87 & 7 & 20 & 44 & 111 & 169 \\
\hline
\end{tabular}

Usually, the value of MER decreases as a function of the conditions of the gasification reactor, in particular the reaction temperature. The value for isothermal systems is lower than for adiabatic systems. The isothermal system presents steps for yield calculated at low temperature when the concentration of the solution increases for both hydrogen production and methane production. This means that increasing the concentration at low temperature has no influence on the amount of heat to be supplied in the system. On the other hand, at high temperature, the increase in concentration decreases the value of MER. This means that the energy intake of glucose contributes to maintain the reactions at high temperature, therefore requires less external energy. In the case of cogeneration, the net heat electricity production follows the same trend. This production is calculated by subtracting to the work delivered by the turbine, the pump work and the compressor work. The increase in temperature and for a given temperature the increase in glucose content increases this net production. This is directly linked to the net gases mass production that allows a much higher combustible gas input into the combustion chamber. In the case of adiabatic reactors, the theoretical combustion temperature is higher than the set temperature for isothermal mode $(1373 \mathrm{~K})$ and thus allows the production of higher power and results in the release offumes at higher temperatures.

\subsection{Energy and exergy analysis}

Energetic calculations have been conducted considering the data from the simulations presented in previous paragraph (mass flows, temperatures, pressure) and the data from the pinch analysis.

In the cases of gas production, the energetic efficiency for each product (Eq. (5)) is calculated with the different lower heating values of the entering and exiting flows, as proposed for instance in the work of Gasafi et al. [28].

$\eta_{i}=\frac{\mathrm{LHV}_{\mathrm{Gasi}} \times \mathrm{Q}_{\mathrm{Gasi}}}{\mathrm{LHV}_{\text {Biomass }} \times \mathrm{Q}_{\text {Biomass }}} \times 100$

with: $Q_{i}$ the mass flows $\left(\mathrm{kg} \mathrm{s}^{-1}\right)$ and $\mathrm{LHV}_{\mathrm{i}}$ the Lower Heating Value $\left(\mathrm{J} \mathrm{kg}^{-1}\right)$. The energy efficiency calculated by several authors for different biomass varies from 45 to $70 \%[1,6,28]$.

The global energy efficiency of gas production systems is calculated by equation 6 .

$\eta_{G i}=\frac{\mathrm{LHV}_{\mathrm{Gasi}} \times \mathrm{Q}_{\mathrm{Gasi}}}{\Delta \mathrm{W}+\mathrm{MER}+\mathrm{LHV}_{\text {Biomass }} \times \mathrm{Q}_{\text {Biomass }}} \times 100$

With MER: minimum heat requirement and $\Delta \mathrm{W}$ : sum of the mechanical power used.

In the case of cogeneration of heat and electricity, Eq. (7) is used for the global energy efficiency.

$\eta_{\mathrm{GCo}}=\frac{\mathrm{P}_{\text {Turbine }}+\mathrm{Q}_{\text {Fumes }}}{\mathrm{MER}+\Delta \mathrm{W}+\mathrm{LHV}_{\text {Biomass }} \times \mathrm{Q}_{\text {Biomass }}} \times 100$

Where: $\mathrm{P}_{\text {Turbine }}$ and $\mathrm{Q}_{\text {Fumes }}$ represent respectively the power recovered at the gas turbine and the heat recovered from the flue gases.

Calculation results for global energy efficiency obtained for hydrogen and methane production are shown in Table 2.

An increase in $\mathrm{H}_{2}$ and $\mathrm{CH}_{4}$ energy efficiency with temperature can be observed. Increasing the concentration of the initial solution has no real effect on product yields. In the case of hydrogen, energy efficiency is the same for both systems studied. In the case of methane, the performance of adiabatic system is higher than that obtained in the isothermal system.

Exergy concept is a powerful tool to analyse the efficiency of a system. The exergy available from heat sources exchanged with the system is calculated by integrating factor Carnot heat flux (Eq. (8)).

$\mathrm{Ex}=\theta \times \mathrm{Q}$

With: $\mathrm{Q}$ the amount of heat exchanged and $\theta$, the Carnot factor: $\theta=1-\frac{T_{1}}{T_{2}}$

Eq. (8) is used for the calculation of exergy for the fumes exiting the system, as well as for the resulting MER. For glucose or gases, the amount of incoming exergy is calculated as the product of its LHV and the flowrate.

The exergy efficiency is calculated according to the definitions in the literature $[29,30]$ as the ratio between the useful and incoming exergies. In our case, systems can exchange exergy with the environment through heat generated $(\mathrm{Q}<0)$, chemical exergy or through

Table 2

Energetic yields (from Eq. (6)).

\begin{tabular}{|c|c|c|c|c|c|c|c|c|c|}
\hline Temperature & $450{ }^{\circ} \mathrm{C}$ & $450{ }^{\circ} \mathrm{C}$ & $450{ }^{\circ} \mathrm{C}$ & $450{ }^{\circ} \mathrm{C}$ & $500{ }^{\circ} \mathrm{C}$ & $600{ }^{\circ} \mathrm{C}$ & $600{ }^{\circ} \mathrm{C}$ & $600^{\circ} \mathrm{C}$ & $600{ }^{\circ} \mathrm{C}$ \\
\hline TOC concentration $\left(\mathrm{g} \mathrm{L}^{-1}\right)$ & 20 & 30 & 60 & 80 & 20 & 20 & 30 & 60 & 80 \\
\hline$\eta_{\mathrm{GH} 2}$ adiabatic $(\%)$ & 54.6 & 57.3 & 57.5 & 51.1 & 74.6 & 78.8 & 80.7 & 77.7 & 89.6 \\
\hline$\eta_{\mathrm{GH} 2}$ isothermal (\%) & 54.6 & 57.3 & 57.5 & 51.1 & 74.6 & 78.8 & 80.7 & 77.7 & 89.6 \\
\hline$\eta_{\mathrm{GCH} 4}$ adiabatic (\%) & 60.5 & 53.9 & 52.1 & 71.0 & 71.0 & 71.5 & 73.0 & 74.7 & 81.2 \\
\hline$\eta_{\mathrm{GCH} 4}$ isothermal (\%) & 59.5 & 52.8 & 51.1 & 69.9 & 69.6 & 70.3 & 71.8 & 73.4 & 79.8 \\
\hline
\end{tabular}


mechanical power used generated $(\mathrm{W}>0)$ [31]. Incoming exergies are thus formed of exergy of the incoming biomass, pumps, compressors and heating (gathered in the MER). Outgoing exergies consist of exergy contained in the product gas stream, turbines, and heat. These definitions lead to Eq. (9) that defines the exergetic efficiency for gas production systems Eq. (9).

$\eta_{\text {Exi }}=\frac{\operatorname{LHV}_{\text {Gasi }} \times \mathrm{Q}_{\mathrm{Gasi}}}{\operatorname{MER} \times \theta+\Delta \mathrm{W}+\mathrm{LHV}_{\text {Biomass }} \times \mathrm{Q}_{\text {Biomass }}} \times 100$

For cogeneration, exergy efficiency is given by Eq. (10).

$\eta_{\text {ExCo }}=\frac{\mathrm{P}_{\text {Turbine }}+\mathrm{Q}_{\text {Fumes }} \times \theta}{\mathrm{MER} \times \theta+\Delta \mathrm{W}+\mathrm{LHV}_{\text {Biomass }} \times \mathrm{Q}_{\text {Biomass }}} \times 100$

For instance, Gasafi et al. [28] calculated the total exergy efficiency of gasification of sewage sludge in supercritical water for hydrogen production is of the order of $52 \%$ exergy efficiency. Calculations by Feng et al. [32] upon the gasification of biomass in supercritical water environment indicate exergy efficiencies of the order of $40.6 \%$. An interesting work on exergy analysis, in the case of supercritical water oxidation of coal, has been proposed by Yan et al. [33].

Table 3 (adiabatic case) and Table 4 (isothermal case) gather respectively the results of energy efficiency and overall exergy efficiency obtained from the simulation of production processes of $\mathrm{H}_{2}, \mathrm{CH}_{4}$ and cogeneration, in adiabatic and isothermal cases.

Tables 3 and 4 show an increase in energy and exergy efficiencies with temperature and also with the initial concentration for all the scenarios. Adiabatic processes yields are higher than the yields for isothermal systems. The results obtained for the process of cogeneration indicate yields ranging from 20 to $85 \%$ and $25-75 \%$ respectively for energy efficiency and exergy in the adiabatic system. In the isothermal system, these yields are lower and they vary between 22 and $72 \%$ and 24-60\% respectively for energy and exergy efficiencies. For cogeneration, as all combustible gases are burnt in the system, there are thus no losses during chemical conversion as in methane or hydrogen production where a part of the carbon is turned into $\mathrm{CO}_{2}$. It is shown here how the coupling of energy and exergy yields can be valuable. Indeed, when in term of energy yields cogeneration appears to be more efficient, the contrary conclusion could be done for exergy. This is due to the important amount of heat available (ranging from 1.5 to 3 times higher than the net electricity production) but at temperature quite low (from 673 to $861 \mathrm{~K}$, in the case of isothermal reactors).

\subsection{Influence of operating parameters through numerical design}

The objective is to quantify the influence of operating parameters and search for optimal conditions. This study is performed on the Nemrod software (France) using the numerical design methodology that have been already successfully used and presented in Lefevre et al. [34] to analyse conversion systems. The shape of the computational domain is spherical and the type of model used is a quadratic model. Factors are the reaction temperature in the gasifier (three levels: 450, 500 and $600{ }^{\circ} \mathrm{C}$ ) and the initial TOC concentration of the glucose

Table 3

Energetic and exergetic yields for the adiabatic cases (calculated from Eqs. (5), (9) and (10)).

\begin{tabular}{|c|c|c|c|c|c|c|c|c|c|c|}
\hline \multirow{2}{*}{\multicolumn{2}{|c|}{$\begin{array}{l}\text { Temperature }{ }^{\circ} \mathrm{C} \\
\text { TOC concentration } \mathrm{g} \mathrm{L}^{-1}\end{array}$}} & \multicolumn{4}{|c|}{450} & \multicolumn{2}{|c|}{500} & \multicolumn{3}{|c|}{600} \\
\hline & & \multirow{2}{*}{$\frac{20}{25}$} & \multirow{2}{*}{$\begin{array}{l}30 \\
28\end{array}$} & \multirow{2}{*}{$\begin{array}{l}60 \\
45\end{array}$} & \multirow{2}{*}{$\begin{array}{l}80 \\
41\end{array}$} & \multirow{2}{*}{$\begin{array}{l}20 \\
33\end{array}$} & \multirow{2}{*}{$\begin{array}{l}20 \\
43\end{array}$} & \multirow{2}{*}{30} & \multirow{2}{*}{60} & \multirow{2}{*}{$\begin{array}{l}80 \\
80\end{array}$} \\
\hline$\eta_{\mathrm{i}}(\%)$ & $\mathrm{H}_{2}$ & & & & & & & & & \\
\hline & $\mathrm{CH}_{4}$ & 28 & 27 & 42 & 56 & 32 & 39 & 49 & 67 & 79 \\
\hline & Cogeneration & 21 & 28 & 40 & 40 & 34 & 48 & 58 & 72 & 85 \\
\hline \multirow[t]{3}{*}{$\eta_{\mathrm{EXi}}(\%)$} & $\mathrm{H}_{2}$ & 31 & 34 & 51 & 46 & 40 & 50 & 60 & 72 & 85 \\
\hline & $\mathrm{CH}_{4}$ & 38 & 35 & 50 & 64 & 41 & 46 & 55 & 72 & 82 \\
\hline & Cogeneration & 25 & 32 & 41 & 39 & 38 & 48 & 56 & 64 & 75 \\
\hline
\end{tabular}

Table 4

Energetic and exergetic yields for the isothermal cases (calculated from equations 5, 9 and $10)$.

\begin{tabular}{|c|c|c|c|c|c|c|c|c|c|c|}
\hline \multirow{2}{*}{\multicolumn{2}{|c|}{$\begin{array}{l}\text { Temperature }{ }^{\circ} \mathrm{C} \\
\text { TOC concentration } \mathrm{g} \mathrm{L}^{-1}\end{array}$}} & \multicolumn{4}{|c|}{450} & \multicolumn{2}{|l|}{500} & \multicolumn{3}{|c|}{600} \\
\hline & & \multirow{2}{*}{$\frac{20}{26}$} & \multirow{2}{*}{$\frac{30}{30}$} & \multirow{2}{*}{$\begin{array}{l}60 \\
46\end{array}$} & \multirow{2}{*}{$\begin{array}{l}80 \\
43\end{array}$} & \multirow{2}{*}{$\begin{array}{l}20 \\
35\end{array}$} & \multirow{2}{*}{$\begin{array}{l}20 \\
42\end{array}$} & \multirow{2}{*}{$\begin{array}{l}30 \\
51\end{array}$} & \multirow{2}{*}{$\frac{60}{61}$} & \multirow{2}{*}{$\begin{array}{l}80 \\
68\end{array}$} \\
\hline$\eta_{\mathrm{i}}(\%)$ & $\mathrm{H}_{2}$ & & & & & & & & & \\
\hline & $\mathrm{CH}_{4}$ & 28 & 28 & 44 & 59 & 32 & 39 & 49 & 64 & 71 \\
\hline & Cogeneration & 22 & 29 & 41 & 41 & 36 & 49 & 61 & 65 & 71 \\
\hline \multirow[t]{3}{*}{$\eta_{\mathrm{EXi}}(\%)$} & $\mathrm{H}_{2}$ & 32 & 36 & 52 & 48 & 43 & 49 & 58 & 67 & 75 \\
\hline & $\mathrm{CH}_{4}$ & 38 & 36 & 51 & 66 & 41 & 46 & 55 & 69 & 76 \\
\hline & Cogeneration & 24 & 30 & 39 & 38 & 37 & 46 & 54 & 57 & 62 \\
\hline
\end{tabular}

solution (four levels: 20, 30, 60 and $80 \mathrm{gL}^{-1}$ ).

Three responses are examined:

- The energy efficiency of the conversion system calculated with Eqs. (6) and (7);

- The exergy efficiency of the conversion system calculated with Eqs. (9) and (10);

- The MER calculated from the pinch analysis.

A multilinear regression was performed with ANOVA method and residue coefficients calculations. The coefficient of determination of the different model representing the fitting of the data varies between 97.2 and $99.8 \%$. This shows a good correlation between the model data and the simulation data. These models can be considered as valid. Contour graphs are given in Supplementary material, Appendix F.

\subsubsection{Analysis of the results of numerical design}

The results discussed in this section are those for the production of $\mathrm{H}_{2}$ and $\mathrm{CH}_{4}$ in the adiabatic case. Increasing the initial concentration of the solution appears to be a good factor to improve energy efficiency as well as exergy efficiency. High temperatures can increase yields as already outlined in the experimental study [17]. A minimum of heat is obtained for higher temperatures but the initial concentration of the solution has no influence on the MER. This point is very interesting because the process could be operated in very large quantities of organic materials in the same way as for solutions with lower concentrations.

In the case of methane production, the variations are substantially similar to those presented in the case of hydrogen production. Energy and exergy efficiencies are highly dependent on high temperatures but also high concentrations. The variation of MER has a dependence on the temperature. A slight effect of concentration can be observed at very high temperature values.

Energy and exergy efficiencies and heat supply for adiabatic cogeneration evolve identically to the previous scenario. The variation in MER in this case depends on the temperature and the initial concentration of the glucose solution.

In all scenarios, for adiabatic cases, the optimum range appears to be slightly decentred on the response surface. The results are interesting because the surfaces obtained for all responses indicate higher values for the two factors studied. Only the minimum heat input in the case of the production of fuel gas does not exhibit sensitivity to the initial concentration of the solution.

The response surfaces obtained for cogeneration isothermal case show an influence of the two factors. The production of methane exhibit a plateau for temperature and a more pronounced slope for the initial concentration influence. The same conclusion is obtained for $\mathrm{H}_{2}$ production.

\subsubsection{Study of the optimal domain}

The aim of desirability study is to find an area of compromise between specifications with simultaneous optimization of multiple 
Table 5

Processes optimum (I for isothermal and A for adiabatic).

\begin{tabular}{lllllll}
\hline & $\mathrm{H}_{2}(\mathrm{I})$ & $\mathrm{H}_{2}(\mathrm{~A})$ & $\mathrm{CH}_{4}(\mathrm{I})$ & $\mathrm{CH}_{4}(\mathrm{~A})$ & Cogen (I) & Cogen (A) \\
\hline $\mathrm{T}\left({ }^{\circ} \mathrm{C}\right)$ & 584 & 626 & 588 & 614 & 584 & 608 \\
$\mathrm{TOC}\left(\mathrm{g} \mathrm{L}^{-1}\right)$ & 58.5 & 51 & 87 & 70 & 63 & 74 \\
$\eta_{\mathrm{Gi}}(\%)$ & 64 & 71 & 74 & 77 & 68 & 83 \\
Desirability (\%) & 100 & 100 & 100 & 100 & 100 & 100 \\
$\eta_{\mathrm{EXi}}(\%)$ & 72 & 80 & 80 & 80 & 60 & 73 \\
Desirability (\%) & 83 & 100 & 100 & 100 & 64 & 87 \\
MER (W) & 154 & 155 & 67 & 106 & 137 & 121 \\
Desirability (\%) & 62 & 64 & 67 & 75 & 68 & 74 \\
Global desirability & 80 & 86 & 94 & 91 & 76 & 86 \\
$\quad(\%)$ & & & & & &
\end{tabular}

responses. The basic desirability function is built to combine the individual needs of each response. It is minimal or zero, when it is out of specification limits, and it is maximal if it fulfils all the desired conditions. To build this function, it is necessary to specify the objectives for each response by setting the basic desires. The characteristics of the overall objective can be altered by adjusting the relative weight of the responses. Once the specified desirability function is calculated, the objective is to find the point that maximizes this function. The initiation of basic desires is done by considering a Derringer transformation unilateral left for targets with positive values and unilateral right for those who have negative or zero values. Energy efficiency is considered with no preference on the target. For the exergy efficiency, the target is set at $80 \%$. For minimum heat input, the target is $0 \mathrm{~W}$. Table 5 presents a summary of the optimum values for all conversion systems simulated in the adiabatic and isothermal cases.

For hydrogen production, in the case of adiabatic conversion, the optimal area is for high initial concentrations and high temperatures. This conclusion is also observed on the response surfaces for exergy efficiency. In this example, the maximum value of desirability is $86 \%$ : this means that all the targets in the responses are not reached. More precisely, the target for optimal exergy efficiency is reached, however, that of MER is not reached. The coordinates of the maximum of desirability are a reaction temperature of $626^{\circ} \mathrm{C}$ and an initial TOC concentration of $51 \mathrm{~g} \mathrm{~L}^{-1}$. The value provided regarding the temperature is outside the scope defined.

Desirability obtained for systems are different for the same process according to whether it is adiabatic or isothermal. They are all less than $100 \%$, meaning that all he targets cannot be reached with the same input conditions. The coordinates of the maximum are outside the boundaries for at least one of the factors. The temperature in all adiabatic simulations is slightly out of bounds. For the production of methane, the initial concentration must be high in order to get the higher value. The best results are those obtained in the case of methane production for an isothermal reactor. The temperature is slightly lower than the maximum value of the defined range and the concentration is maximum. The desirability is still not $100 \%$. The results of the responses obtained in this case are: a minimum heat input of $66.5 \mathrm{~W}$ and exergy efficiency of $80 \%$.

In the case of cogeneration, the simulation for adiabatic conversion give a low value but close to $80 \%$ and higher initial factors for concentration and lower desirability for temperature in this case than in the isothermal system. The response surfaces show remarkable results, the possibility of using solutions with very high concentrations of organic matter is noted. The reaction temperature has a very important influence on the variations of all the responses studied. In all cases, maximum temperatures favour the conversion of matter and therefore exergy efficiency.

\section{Conclusion and prospects}

Different scenarios are simulated by software modules in Prosim.
Implementing these processes is based on experimental results. The results of the analysis indicate the need to supply heat for all systems, except for cogeneration. The minimum heat requirements MER are dependent on the temperature of the gasification reactor while the initial concentration seems to have a slighter influence.

Energy yields indicate better results in adiabatic conversion systems; they differ according to the scenario and range from 30 to $90 \%$. The best results are obtained at higher temperature.

Numerical design and desirability functions indicate a temperature and concentrations dependence.

The MER mainly depends on temperature. The study of the optimal range gives desirability ranging from 76 to $94 \%$. All targets are not reached. Only the desirability in the case of the production of methane give values higher than $90 \%$.

This method give very interesting results for an accurate energetic analysis of biomass valorisation and could be applied to many other types of biomass.

\section{Appendix A. Supplementary data}

Supplementary data associated with this article can be found, in the online version, at http://dx.doi.org/10.1016/j.supflu.2017.10.002

\section{References}

[1] Y. Calzavara, C. Joussot-Dubien, G. Boissonnet, S. Sarrade, Evaluation of biomass gasification in supercritical water process for hydrogen production, Energy Convers. Manage. 46 (2005) 615-631.

[2] P.E. Savage, Q. Guan, G. Huelsman, Biomass gasification in supercritical water, Abstracts Pap. Am. Chem. Soc. 244 (2012) 128-136.

[3] M.J. Antal, S.G. Allen, D. Schulman, X.D. Xu, R.J. Divilio, Biomass gasification in supercritical water, Ind. Eng. Chem. Res. 39 (2000) 4040-4053.

[4] G. Van Rossum, B. Potier, S.R.A. Kersten, W.P.M. van Swaaij, Catalytic gasification of dry and wet biomass, Catal. Today 145 (2009) 10-18.

[5] F.L.P. Resende, M.E. Neff, P.E. Savage, Noncatalytic gasification of cellulose in supercritical water, Energy Fuels 21 (2007) 3637-3643.

[6] Y. Matsumura, T. Minowa, B. Potic, S.R.A. Kersten, W. Prins, W.P.M. van Swaaij, Biomass gasification in near- and super-critical water: status and prospects, Biomass Bioenergy 29 (2005) 269-292.

[7] S. Letellier, F. Marias, P. Cezac, J.P. Serin, Gasification of aqueous biomass in supercritical water: a thermodynamic equilibrium analysis, J. Supercrit. Fluids 51 (2010) 353-361.

[8] H.Q. Tang, K. Kitagawa, Supercritical water gasification of biomass: thermodynamic analysis with direct Gibbs free energy minimization, Chem. Eng. J. 106 (2005) 261-267.

[9] W. Feng, H.J. van der Kooi, J.D.S. Arons, Biomass conversions in subcritical and supercritical water: driving force, phase equilibria, and thermodynamic analysis, Chem. Eng. Process. 43 (2004) 1459-1467.

[10] H. Schmieder, J. Abeln, N. Boukis, E. Dinjus, A. Kruse, M. Kluth, G. Petrich, E. Sadri, M. Schacht, Hydrothermal gasification of biomass and organic wastes, J. Supercrit. Fluids 17 (2000) 145-153.

[11] J. Szargut, M.D. Steward, Exergy Analysis of Thermal. Chemical and Metallurgical Processes, Hemisphere Publishing Corporation, New York, Washington, Philadelphia, London, 1988.

[12] O. Yakaboylu, J. Harinck, K.G. Smit, Supercritical water gasification of biomass: a literature and technology overview, Energies 8 (2015) 859-894.

[13] P. Casademont, M. Garcia-Jarana, J. Sanchez-Oneto, Jezabel, Supercritical water gasification: a patents review, Rev. Chem. Eng. 33 (2017) 237-261.

[14] F. Marias, S. Letellier, P. Cezac, J.P. Serin, Energetic analysis of gasification of aqueous biomass in supercritical water, Biomass Bioenergy 35 (2011) 59-73.

[15] Q. Guan, C.H. Wei, X.D. Chai, P. Ning, S.L. Tian, J. Gu, Q. Chen, R. Miao, Energetic analysis of gasification of biomass by partial oxidation in supercritical water, Chin. J. Chem. Eng. 23 (2015) 205-212.

[16] W. Wan, An innovative system by integrating the gasification unit with the supercritical water unit to produce clean syngas: effects of operating parameters, Int. J. Hydrogen Energy 41 (2016) 14573-14582.

[17] F. Ondze, O. Boutin, J.C. Ruiz, J.H. Ferrasse, F. Charton, Supercritical water gasification of beet residues: from batch to continuous reactor, Chem. Eng. Sci. 123 (2015) 350-358.

[18] R. Toonssen, N. Woudstra, A.H.M. Verkooijen, Exergy analysis of hydrogen production plants based on biomass gasification, Int. J. Hydrogen Energy 33 (2008) 4074-4082.

[19] M.K. Cohce, I. Dincer, M.A. Rosen, Energy and exergy analyses of a biomass-based hydrogen production system, Bioresour. Technol. 102 (2011) 8466-8474.

[20] D. Ruthven, S. Farooq, Pressure Swing Adsorption, (1994) New York.

[21] M. Gassner, F. Marechal, Thermo-economic process model for thermochemical production of Synthetic Natural Gas (SNG) from lignocellulosic biomass, Biomass Bioenergy 33 (2009) 1587-1604. 
[22] M. Gassner, F. Marechal, Thermo-economic optimisation of the polygeneration of synthetic natural gas (SNG), power and heat from lignocellulosic biomass by gasification and methanation, Energy Environ. Sci. 5 (2012) 5768-5789.

[23] M. Gassner, F. Vogel, G. Heyen, F. Marechal, Optimal process design for the polygeneration of SNG, power and heat by hydrothermal gasification of waste biomass: thermo-economic process modelling and integration, Energy Environ. Sci. 4 (2011) $1726-1741$.

[24] A. Duret, C. Friedli, F. Marechal, Process design of Synthetic Natural Gas (SNG) production using wood gasification, J. Clean. Prod. 13 (2005) 1434-1446.

[25] M. Gassner, F. Vogel, G. Heyen, F. Marechal, Optimal process design for the polygeneration of SNG, power and heat by hydrothermal gasification of waste biomass: process optimisation for selected substrates, Energy Environ. Sci. 4 (2011) $1742-1758$.

[26] B. Linnhof, Thermodynamics analysis in the design of process networks. PhD thesis, University, (1979).

[27] J.P. Gourlia, La méthode du pincement ou exploitation des diagrammes température/enthalpie, Notions de base, Revue Générale de thermique 327 (1989) $33-42$.

[28] E. Gasafi, L. Meyer, L. Schebek, Exergetic efficiency and options for improving sewage sludge gasification in supercritical water, Int. J. Energy Res. 31 (2007)
346-363.

[29] P. Grassman, Zur allgemeinen definition des wirkungsgrades, Chemikal Ingenieur Technik 5 (1950) 70-73.

[30] M. Sorin, B. Spinner, D. Stitou, Thermodynamic techniques for the conceptual design of thermochemical refrigerators using two salt materials, Chem. Eng. Sci. 57 (2002) 4243-4251.

[31] R.L. Smith, T. Adschiri, K. Arai, Energy integration of methane's partial-oxidation in supercritical water and exergy analysis, Appl. Energy 71 (2002) 205-214.

[32] F. Feng, G.H. Song, L.H. Shen, J. Xiao, Energy efficiency analysis of biomass-based synthetic natural gas production process using interconnected fluidized beds and fluidized bed methanation reactor, Clean Technol. Environ. Policy 18 (2016) 965-971.

[33] Q.H. Yan, Y.W. Hou, J. Luo, H. Miao, H. Zhang, The exergy release mechanism and exergy analysis for coal oxidation in supercritical water atmosphere and a power generation system based on the new technology, Energy Conversion Manage. 129 (2016) 122-130.

[34] S. Lefevre, O. Boutin, J.H. Ferrasse, A. Viand, Energetic optimization of wet air oxidation process using experimental design coupled with process simulation, Energy 41 (2012) 175-183. 